\title{
JOURNAL OF MEDICAL
}

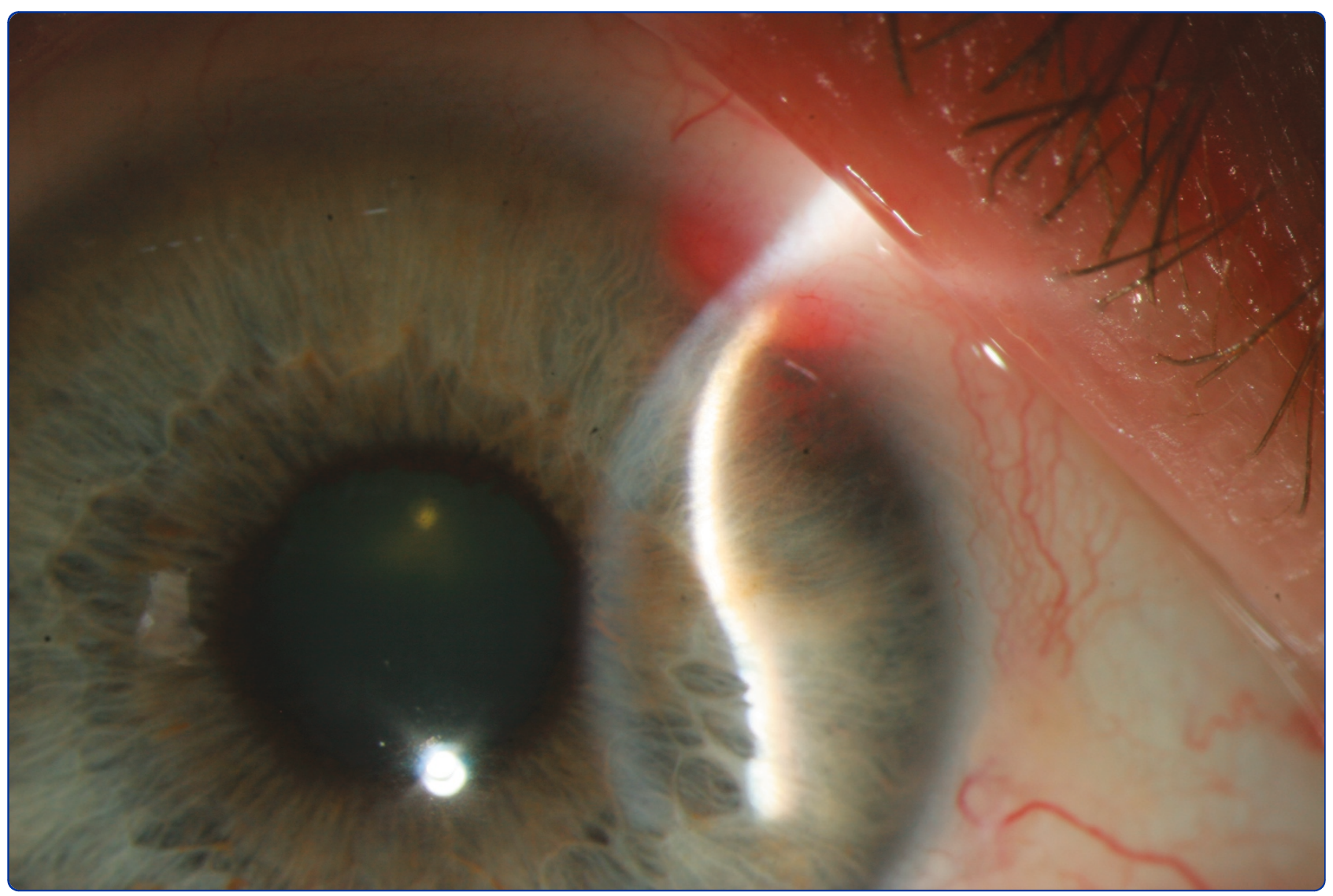

Renal cell carcinoma metastasis to the ciliary body responds to proton beam radiotherapy: a case report

Alasil et al. 


\title{
Renal cell carcinoma metastasis to the ciliary body responds to proton beam radiotherapy: a case report
}

\author{
Tarek Alasil', Bahram Khazai, Lilia Loredo and Michael E Rauser
}

\begin{abstract}
Introduction: We report an unexpected presentation of metastatic renal cell carcinoma (RCC) to the ciliary body and an interesting response to proton beam radiotherapy.

Case presentation: We encountered a case of angle-closure glaucoma as the initial presentation of ocular metastasis to the ciliary body in a 65-year-old Caucasian man who had undergone right radical nephrectomy for RCC 15 years earlier. He underwent YAG (yttrium aluminium garnet) laser peripheral iridotomy while further metastatic workup took place. His condition was eventually diagnosed as stage IV metastatic RCC of the clear cell type and involved multiple sites, including the ciliary body, brain, lungs, liver, and pancreas. The progression of RCC metastasis to the ciliary body was studied for 16 months. The ciliary body mass continued to grow despite systemic treatment with temsirolimus and interleukin-2 and intravitreal injections of bevacizumab. The tumor size peaked at $6.11 \times 6.06 \mathrm{~mm}$ before the start of proton therapy, which reduced the tumor size to $5.07 \times 4.39 \mathrm{~mm}$.

Conclusions: RCC can produce metastases involving unusual sites many years after resection of the primary tumor. Proton therapy was found to be effective in treating RCC metastasis to the ciliary body in settings in which other treatment modalities failed.
\end{abstract}

\section{Introduction}

Renal cell carcinoma (RCC) accounts for approximately $85 \%$ of primary renal neoplasms and represents approximately $3 \%$ of all adult malignancy [1]. The most common sites of metastasis are the lung (50\%) and the bone (33\%), but RCC has been documented to metastasize to every organ and site in the body by hematogenous spread. The interval between RCC systemic and ocular presentations varies and may become so prolonged as to obscure the relationship between the ocular metastasis and the primary RCC tumor [2]. In a pathologic survey, Ferry and Font [3] demonstrated that only seven out of 196 cases of ocular metastatic carcinoma originated from RCCs. Ocular metastases from RCC are most likely to involve the iris [4], ciliary body [5], and choroids, although eyelid and orbital metastases have been described [6].

\footnotetext{
* Correspondence: tarekalasil@hotmail.com

* Correspondence: tarekalasil@hotmail.com 92354, USA
}

(c) 2011 Alasil et al; licensee BioMed Central Ltd. This is an Open Access article distributed under the terms of the Creative Commons Attribution License (http://creativecommons.org/licenses/by/2.0), which permits unrestricted use, distribution, and reproduction in any medium, provided the original work is properly cited. ondary to ciliary body metastasis in a patient who underwent radical nephrectomy for RCC 15 years earlier. Also, we review the different treatment modalities we used to treat the ocular metastasis.

\section{Case presentation}

A 65-year-old Caucasian man presented to our emergency department and complained of sudden-onset blurry vision and pain in his right eye. He reported associated nausea and a right-sided headache. His medical history was significant for RCC, for which he had undergone right radical nephrectomy 15 years earlier. After the initial nephrectomy, he had completed 10 years of surveillance, after which he was thought to be diseasefree.

At presentation, his best corrected visual acuities were 20/50 in his right eye (oculus dexter, or OD) and 20/20 in his left eye (oculus sinister, or OS). The intraocular pressures by applanation tonometry were $50 \mathrm{~mm} \mathrm{Hg}$ OD and $14 \mathrm{~mm} \mathrm{Hg}$ OS. The results of a left eye exam 
were unremarkable. A slit-lamp exam of his right eye demonstrated a red mass that was located in the superior nasal aspect of his iris at one to three o'clock and that was associated with dilated episcleral feeder vessels (Figure 1a). A gonioscopy showed a closed angle with the iris bowing forward to the superior nasal sector of the anterior chamber angle. A high-frequency immersion B-scan ultrasonography of his right eye revealed a ciliary body mass, which was pushing his iris forward toward his cornea (Figure 2a). An iris angiography of his right eye showed an area of hyperfluorescence over the area of his tumor (Figure 1b). A fundus examination of his right eye showed no evidence of choroidal or retinal involvement.
His condition was diagnosed as acute angle-closure glaucoma (AACG) secondary to a ciliary body mass in his right eye. He was started on timolol, acetazolmide, and latanoprost followed by a YAG (yttrium aluminium garnet) laser peripheral iridotomy to lower the intraocular pressure.

The results of a further metastatic workup were consistent with a stage IV RCC that was of the clear cell type (Figure 3 ) and that involved the ciliary body, brain, lungs, liver, and pancreas.

The ciliary body mass continued to grow despite systemic treatment with temsirolimus (mammalian target of rapamycin inhibitor) [7] and interleukin-2 (IL-2) (Figure 1c), but the extraocular metastasis started to shrink. Later,

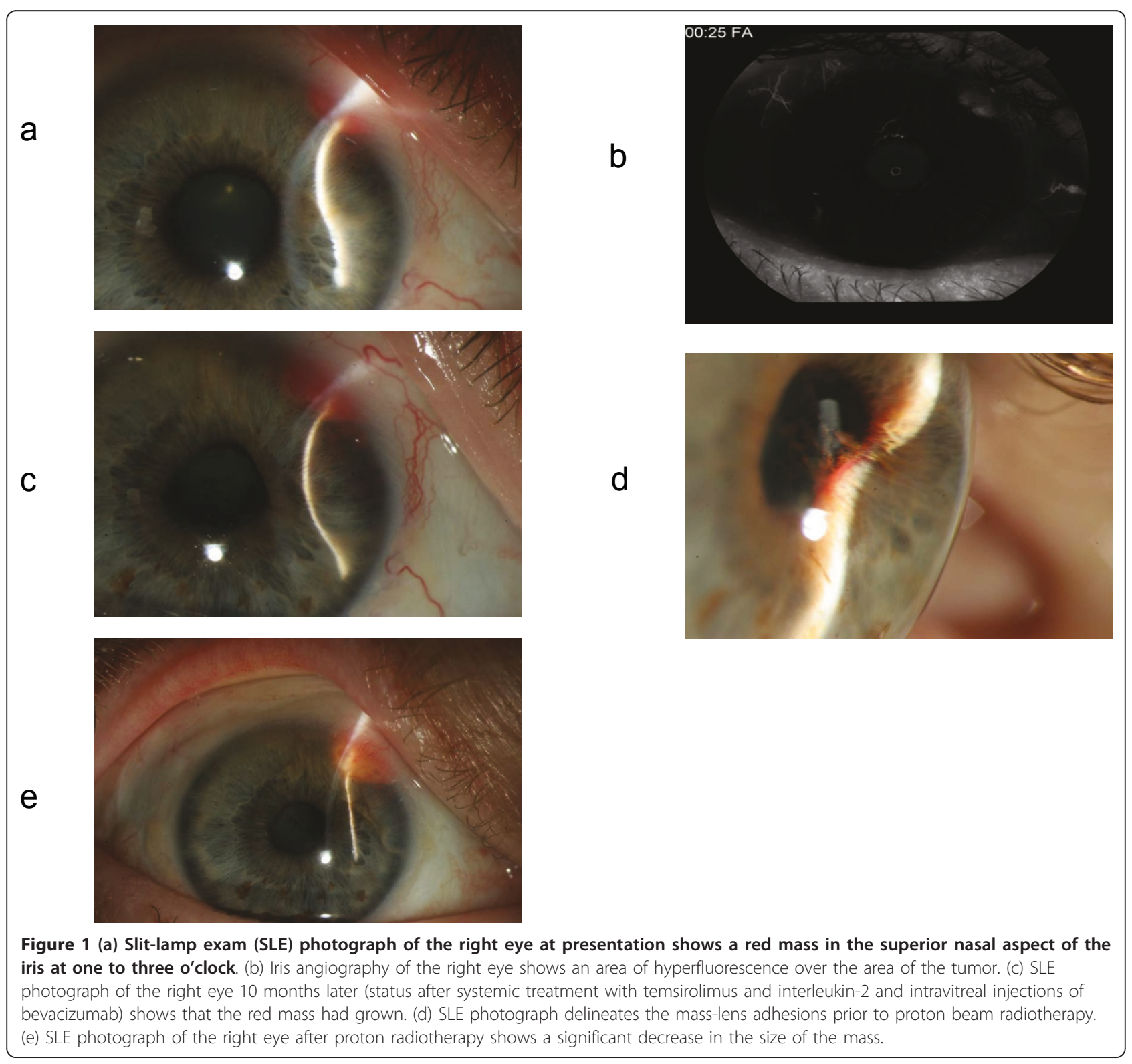




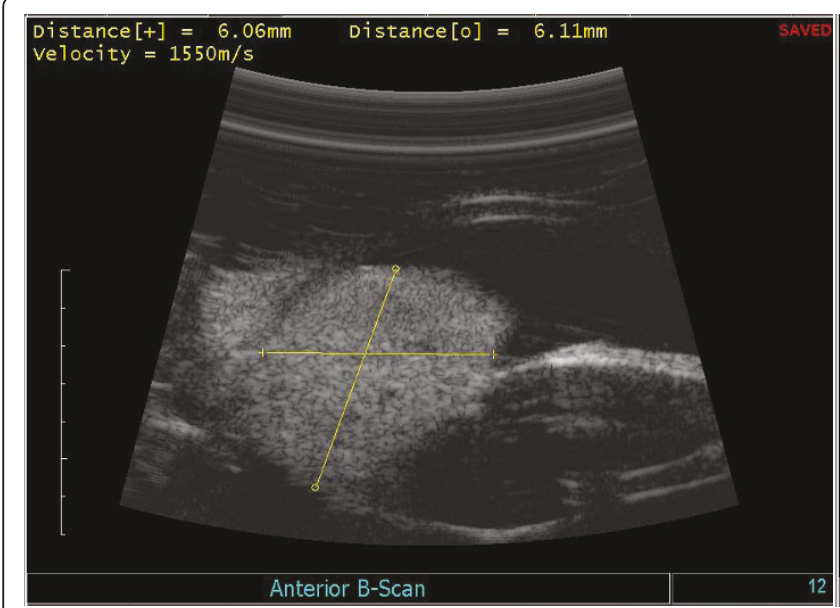

a

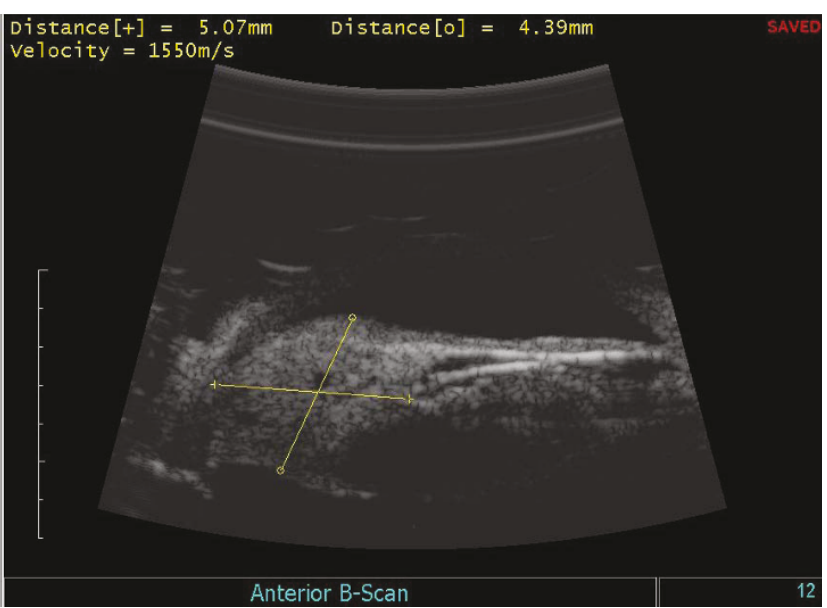

b

Figure 2 (a) High-frequency immersion B-scan ultrasonography of the right eye reveals the ciliary body mass at a peak size of $6.11 \times$ $6.06 \mathrm{~mm}$. (b) B-scan ultrasonography after proton radiotherapy reveals the regression of the ciliary body mass size to $5.07 \times 4.39 \mathrm{~mm}$.

two intravitreal injections of bevacizumab failed to slow the growth of the mass, and the tumor size peaked at 6.11 $\times 6.06 \mathrm{~mm}$ (Figure 2a). Some adhesions have developed between the mass and the lens (Figure 1d).

Lastly, proton radiotherapy was administered. Tantalum clips were placed to outline the posterior margin of the tumor. Our patient received a total of 30 cobalt gray equivalents (CGE) in three fractions given over the course of six calendar days. As a result, the tumor size decreased to $5.07 \times 4.39 \mathrm{~mm}$ (Figures $1 \mathrm{e}$ and $2 \mathrm{~b}$ ). Later,

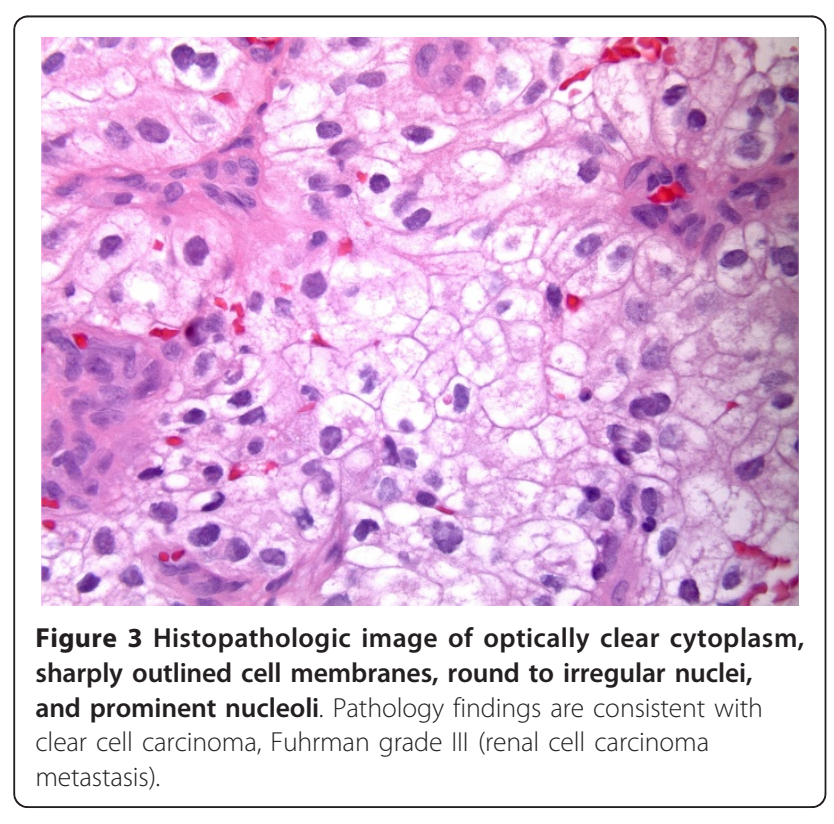

our patient underwent an uneventful cataract extraction and an intraocular lens placement in his right eye. His current visual acuity in his right eye is $20 / 40$.

\section{Discussion}

The mechanism of ocular spread in RCC is presumed to take place through venous diffusion within the small chroidal vessels, and neoplastic cells travel as emboli [8]. Simultaneous bilateral iris metastases from RCC were described by Wizinski and colleagues [4]. Two cases of spontaneous disappearance of choroidal metastasis from RCC after nephrectomy have been described $[9,10]$. Shome and colleagues [11] reported a case of iris metastasis from RCC 14 months after a right nephrectomy. Mancini and colleagues [8] reported a case of left ciliary body metastasis in a 42-year-old man who had undergone a left radical nephrectomy for conventional RCC six years earlier. Our patient is unusual because, before he presented with AACG, he was thought to be diseasefree for 15 years after nephrectomy but he was eventually discovered to have widespread RCC metastasis. Although the extraocular metastasis showed a reasonable response to systemic temsirolimus and IL-2, the ciliary body metastasis failed to do so. One theory may question the bioavailability of these systemic agents in the ciliary body circulation system.

Primary RCC produces angiogenic growth factors (such as basic fibroblastic growth factor and vascular endothelial growth factor), which are responsible for tumor growth, proliferation, metastases, and survival through high serum levels [12]. Unfortunately, our 
patient's tumor continued to grow despite intravitreal injections of bevacizumab (anti-vascular endothelial growth factor).

The prognosis of metastatic RCC is generally poor; median survival is 10 months and five-year survival is less than 5\% [13,14]. Our patient has survived for 16 months with an extraocular response to the systemic temsirolimus and IL-2. His affected eye maintained visual acuity and the ciliary body mass regressed in response to the proton radiotherapy followed by successful cataract surgery.

Several urologists advocated RCC surveillance for at least 10 years after the initial nephrectomy. Others concluded that follow-up for life is reasonable [15-20]. Our case report would emphasize such extended surveillance as long as it is individualized and cost-conscious.

\section{Conclusions}

We present an interventional case report in which the progression of RCC metastasis to the ciliary body was studied for 16 months. The response to different treatment modalities was investigated. The ciliary body mass continued to grow despite systemic treatment with temsirolimus and IL-2 and intravitreal injections of bevacizumab. The tumor size peaked at $6.11 \times 6.06 \mathrm{~mm}$ before the start of proton therapy, which reduced the tumor size to $5.07 \times 4.39 \mathrm{~mm}$. To the best of our knowledge, this is the first case report of a ciliary body metastasis from RCC that responded to proton radiotherapy after other treatment modalities had failed.

\section{Consent}

Written informed consent was obtained from the patient for publication of this case report and any accompanying images. A copy of the written consent is available for review by the Editor-in-Chief of this journal.

\section{Abbreviations \\ AACG: acute angle-closure glaucoma; IL-2: interleukin-2; OD: oculus dexter (right eye); OS: oculus sinister (left eye); RCC: renal cell carcinoma.}

\section{Authors' contributions}

TA analyzed and interpreted the patient data and wrote the manuscript. BK helped to gather the data and write the manuscript. LL was the radiation oncologist who treated our patient with proton beam radiotherapy. MER was the attending ophthalmologist who evaluated our patient, performed the bevacizumab intravitreal injections, and coordinated the proton beam radiotherapy. All authors have read and approved the final manuscript.

\section{Competing interests}

The authors declare that they have no competing interests.

\section{References}

1. Garnick MB, Richie JP: Primary neoplasms of the kidney and renal pelvis. In Disease of the Kidney. Volume 1.. 5 edition. Edited by: Schrier RW, Gottschalk CW. Boston: Little, Brown; 1993.

2. Haimovici R, Gragoudas ES, Gregor Z, Pesavento RD, Mieler WF, Duker JS: Choroidal metastases from renal cell carcinoma. Ophtalmol 1997, 104:1152-1158.

3. Ferry AP, Font RL: Carcinoma metastatic to eye and orbit: a clinicopathologic study of 27 cases. Ophtalmol 1974, 92:276-286.

4. Wizinski $P$, Rootman J, Wood W: Simultaneous bilateral iris metastases from renal cell carcinoma. Am J Optalmol 1981, 92:206-209.

5. Laszczyk WA: Metastatic tumor of the ciliary body-hypernephroma. Ophtalmologica 1975, 170:543-547.

6. Kindermann WR, Shields JA, Eiferman RA: Metastatic renal cell carcinoma to the eye and adnexae: a report of three cases and review of the literature. Ophthalmol 1981, 88:1347-1350.

7. Kapoor A, Figlin RA: Targeted inhibition of mammalian target of rapamycin for the treatment of advanced renal cell carcinoma. Cancer 2009, 115:3618-3630.

8. Mancini V, Battaglia M, Lucarelli G, Di Lorenzo V, Ditonno P, Bettocchi C, Selvaggi FP: Unusual solitary metastasis of the ciliary body in renal cell carcinoma. Int J Urol 2008, 15:363-365.

9. Langmann G, Mullner K: Spontaneous regression of choroidal metastasis from renal cell carcinoma. Br J Opthalmol 1994, 78:883.

10. Hammad AM, Paris GR, van Heuven WAJ, Thompson IM, Fitzsimmons TD: Spontaneous regression of choroidal metastasis from renal cell carcinoma. Am J Ophthalmol 2003, 135:911-913.

11. Shome D, Honavar SG, Gupta P, Vemuganti GK, Reddy PV: Metastasis to the eye and orbit from renal cell carcinoma: a report of three cases and review of literature. Surv Ophthalmol 2007, 52:213-223, Review.

12. Dosquet $C$, Coudert MC, Lepage E, Cabane J, Richard F: Are angiogenic factors, cytokines, and soluble adhesion molecules prognostic factors in patients with renal cell carcinoma. Clin Cancer Res 1997, 3(12 Pt 1):2451-2458.

13. Motzer RJ, Mazumdar M, Bacik J, Berg W, Amsterdam A, Ferrara J: Survival and prognostic stratification of 670 patients with advanced renal cell carcinoma. J Clin Oncol 1999, 17:2530-2540.

14. Clement JM, McDermott DF: The high-dose aldesleukin (IL-2) "select" trial: a trial designed to prospectively validate predictive models of response to high-dose IL-2 treatment in patients with metastatic renal cell carcinoma. Clin Genitourin Cancer 2009, 7:E7-E9.

15. Abara E, Chivulescu L, Clerk N, Cano P, Goth A: Recurrent renal cell cancer: 10 years or more after nephrectomy. Can Urol Assoc J 2010, 4:E45-E49.

16. Montie JE: Follow-up after partial and total nephrectomy for renal cell carcinoma. Urol Clin North Am 1994, 21:589-592.

17. Hafez KS, Novick AC, Campbell SC: Patterns of tumour recurrence and guidelines for follow-up after nephron-sparing surgery for sporadic renal cell carcinoma. J Urol 1997, 157:2067-2070.

18. Ljungberg B, Alamdari FI, Rasmuson T, Roos G: Follow-up guidelines for non-metastatic renal cell carcinoma based on the occurrence of metastases after radical nephrectomy. BJU Int 1999, 84:405-411.

19. Stephenson AJ, Chetner MP, Rourke K, Gleave ME, Signaevsky M, Palmer B, Kuan J, Brock GB, Tanguay S: Guidelines for the surveillance of localized renal cell carcinoma based on the patterns of relapse after nephrectomy. J Urol 2004, 172:58-62.

20. Ljungberg B, Hanbury DC, Kuczyk MA, Merseburger AS, Mulders PF, Patard JJ, Sinescu IC, European Association of Urology Guideline Group for renal cell carcinoma: Renal cell carcinoma guideline. Eur Uro 2007, 51:1502-1510

doi:10.1186/1752-1947-5-345

Cite this article as: Alasil et al:: Renal cell carcinoma metastasis to the ciliary body responds to proton beam radiotherapy: a case report. Journal of Medical Case Reports 2011 5:345. 